\title{
Appraisal of clinical practice guidelines on community-acquired pneumonia in children with AGREE II instrument
}

\author{
Zhenwei Xie ${ }^{1,2 \dagger}$, Xiaoling Wang ${ }^{1 \dagger}$, Lin Sun ${ }^{3}$, Jun Liu ${ }^{4}$, Yan Guo ${ }^{4}$, Baoping Xu ${ }^{4}$, Libo Zhao ${ }^{1 *}$ and Adong Shen ${ }^{3^{*}}$
}

\begin{abstract}
Background: Community-acquired pneumonia (CAP) remains a major cause of morbidity and mortality worldwide among children. The growing number of guidelines have been accompanied with a growing concern about variance and conflicts among guideline recommendations. There is a need to critically appraise clinical practice guidelines (CPGs) in order to ensure safe and effective practices.

Methods: A literature search was systematically conducted in English and Chinese major academic databases (from January 2000 to March 2015). CPGs related to CAP in children were evaluated by four independent assessors, according to AGREE II instruments. Standardized domain scores were calculated for each guideline. Inter-rater reliability was assessed by intraclass correlation coefficient. The software used for analysis was SPSS 17.0.

Results: A total of 10 guidelines met the inclusion criteria and were appraised. Scope and purpose (69.03 \%) and clarity of presentation (83.33\%) achieved relative high scores, while the scores of the other four domains were low: stakeholder involvement (42.78\%), rigour of development (44.95\%), applicability (37.60\%), and editorial independence (23.74 \%). 3 guidelines were strongly recommended as a result of the overall scores were greater than $60 \%$.

Conclusion: The qualities of CPGs for CAP in children were generally acceptable with several flaws. Stakeholder involvement, rigour of development, applicability and editorial independence should be considered and well described in the future development of CPGs.
\end{abstract}

Keywords: Clinical practice guidelines, Community-acquired pneumonia, Children, Quality assessment, AGREE II

\section{Background}

Community-acquired pneumonia (CAP) is defined as an acute infection of lower respiratory tract occurring outside hospital. It remains a major cause of morbidity and mortality among children in developing and developed countries. In developing countries, CAP has an incidence of 0.29 episodes per child-year and a mortality rate of $1.3-2.6 \%[1,2]$. The incidence of CAP is lower in developed countries, with an incidence of about 0.05

\footnotetext{
*Correspondence: libozhao2011@163.com; shenad16@hotmail.com ${ }^{\dagger}$ Equal contributors

'Department of Pharmacy, Beijing Children's Hospital, Capital Medical University, Beijing 100045, China

${ }^{3}$ Key Laboratory of Pediatric Respiratory Infection Diseases, Beijing Pediatric Research Institute, Beijing Children's Hospital, Capital Medical University, Beijing 100045, China

Full list of author information is available at the end of the article
}

episodes per child-year, however, it is still one of the leading causes of hospitalization [3, 4]. In certain conditions, it would occur repeatedly and cause harm to children without proper and complete treatments. Meantime, it will bring heavy burden for national public health care systems.

Guidelines for the management of CAP in children have been increasingly produced and disseminated in recent years. Generally, globalization and uniformity between centers worldwide in patient management has become a trend. However, acceptance of evidence-based medicine (EBM) varies around the world. The growing number of guidelines has been accompanied with a growing concern about variance and conflicts among guideline recommendations. Therefore, there can be huge differences between countries or regions in respect 
to guideline qualities. Hence, it is urgent to identify existing high quality guidelines and make guideline developers follow methodological standards while developing guidelines.

The appraisal of guidelines for research and evaluation II (AGREE II), consisting of 6 domains covering 23 key items, is initially developed from AGREE and updated in 2010. The purpose of this instrument is to evaluate the strengths and limitations of guidelines; to provide methodology for development of guidelines; and to present guidance for reporting recommendations. It is a widelyused instrument and remains the current golden standard for guideline appraisal $[5,6]$.

The quality of CAP guidelines has not been systematically evaluated till now. Thus, the aim of this study was to access the available guidelines for the treatment of children with CAP and to determine the methodological quality and reliability of guidelines.

\section{Methods}

\section{Literature search}

A literature search was systematically conducted in English and Chinese major academic databases (from January 2000 to March 2015). English databases were MEDLINE, EMBASE, Guidelines International Network (GIN), National Guideline Clearinghouse (NGC), Chinese databases were Chinese Biomedical Literature Database (CBM), China National Knowledge Internet (CNKI), VIP Database and Wanfang Database. Key words were "communityacquired", "pneumonia", "children", "pediatric", "guideline", "guidance", "recommendation", "management", and "consensus".

\section{Inclusion and exclusion criteria}

Guidelines published in Chinese or English, which addressed diagnoses and treatments of CAP for children under 18 years of age were included. Guidelines that are systematic reviews, editorials, short summaries, and other literature explaining or evaluating guidelines were excluded. If guidelines have been fully updated, the latest version were evaluated and the old versions were excluded.

\section{Data extraction}

Two of the investigators (Z.W.X and L.B.Z) searched the database, selected guidelines independently and determined if they warranted inclusion in this study and then extracted general characteristics of the guideline. Disagreements were resolved by consulting a third expert opinion (A.D.S). The following information was extracted, such as title of guidelines, country or region, publication date, affiliation or organization, developed method, quality of evidence and filled in an established standard table on Microsoft Excel 2013.

\section{Appraisal guidelines}

The AGREE II instrument was used to assess the methodological quality of included guidelines. It contains 23 key items of 6 domains, such as scope and purpose, stakeholder involvement, rigour of development, clarity of presentation, applicability, editorial independence, and overall guideline assessment. Each item was scored on a scale of $1-7$, with 1 being strongly disagree and 7 being strongly agree. Each domain was calculated by summing up all the scores of the individual items in a domain and then standardizing as follows: (obtained score - minimal possible score) / (maximal possible score - minimal possible score).

Quality assessment were performed independently by four trained reviewers (Z.W. X, L.S, J.L, and Y.G). They conducted an independent review of the quality of each eligible guideline. Disagreement between reviewers was resolved through consensus or by consulting an independent expert adjudicator (L.B.Z). Final average appraisal scores and standard deviations for each domain and scaled domain percentages were calculated.

Intraclass correlation coefficient (ICC) was used as a measure of agreement between reviewers. The ICC values was carried out by SPSS v.17.0 and applied to each guidelines.

Finally, the overall guideline assessment was evaluated. A guideline would be "recommended" if overall scores were greater than $60 \%$, "recommended with modifications" at scores between $30 \%$ and $60 \%$, and "not recommended" at scores less than $30 \%$.

\section{Statistical analysis}

Standardized domain scores were calculated according to methods described in the AGREE II user manual. A descriptive statistical analysis was used to summarize the data. Subgroup comparison between evidencebased guidelines and non evidence-based guidelines were performed by t-test. All tests were two-sided, and $P$ values $<0.05$ were considered statistically significant. All statistics were calculated using SPSS v.17.0.

\section{Results}

A total of 827 records were identified through comprehensive database search and 22 additional records more were identified through Google search engine. 56 were exclude due to duplication, and the remaining 771 were screened by titles and abstracts. 88 were screened by full text articles for eligibility. 42 review articles, 6 guidelines before 2000, 13 interpretation of guidelines, 9 outcome on empirical treatments, 2 old version, 1 involving other disease guideline, 2 adult guidelines, 2 old version (Canadian 97, and Thorax 2009) and 3 other foreign languages (Brazilian, Spanish and Italian guidelines) were excluded. Finally, 10 guidelines were identified and 
involved in the analysis [7-17]. The details of review process was summarized in Fig. 1. The characteristics of each included guideline were presented in Table 1.

\section{Scope and purpose}

This domain addressed the overall objectives, health issues and target population. The score of this domain was relatively high (mean $69.03 \%$, range: 23.61$95.83 \%$ ), indicating most guidelines met the criteria of this domain.

\section{Stakeholder involvement}

This domain assess whether the relevant professional group is represented, the patients' views and preference has been sought, and the definition of target users of the guideline are clearly defined. The score of this domain was $42.78 \%$ (range: 9.70-76.39\%). A few guidelines $[7,8,10,13,16,17]$ could describe the relevant professional group, however, few guidelines seek the preference of target populations.

\section{Rigour of development}

This domain is the core of guideline methodology and mainly focus on the method of evidence search, grading, summarizing and the formulation of the recommendation. The score of scope was $44.95 \%$ (range: 17.19-79.69\%).

\section{Clarify of presentation}

This domain evaluates the presentation and the format. The score of this domain was 83.33 \% (range: 69.44$94.44 \%$ ). Most guidelines recommendations were specific. Different options for management of the condition were clearly presented, and key recommendation was easily identifiable.

\section{Applicability}

This domain discusses the organization barriers, cost implications and monitoring criteria. The assessment result was $37.50 \%$ (range: 17.71-61.46\%). Most guidelines failed to consider it during the guideline development.

\section{Editorial independence}

This domain focuses on the funding issues and competing interests of all contributing members. The score of this domain was $23.74 \%$ (range: 0-87.50 \%). Both evidence-based guidelines and non evidence-based guidelines achieved low scores in this domain.

\section{Agreement among reviewers}

ICC for each guideline is listed in Table 2. Eight of 10 ICC values were $(>75 \%)$ excellent. No ICC values were less than $45 \%$. The reliability of this reviewers were acceptable.

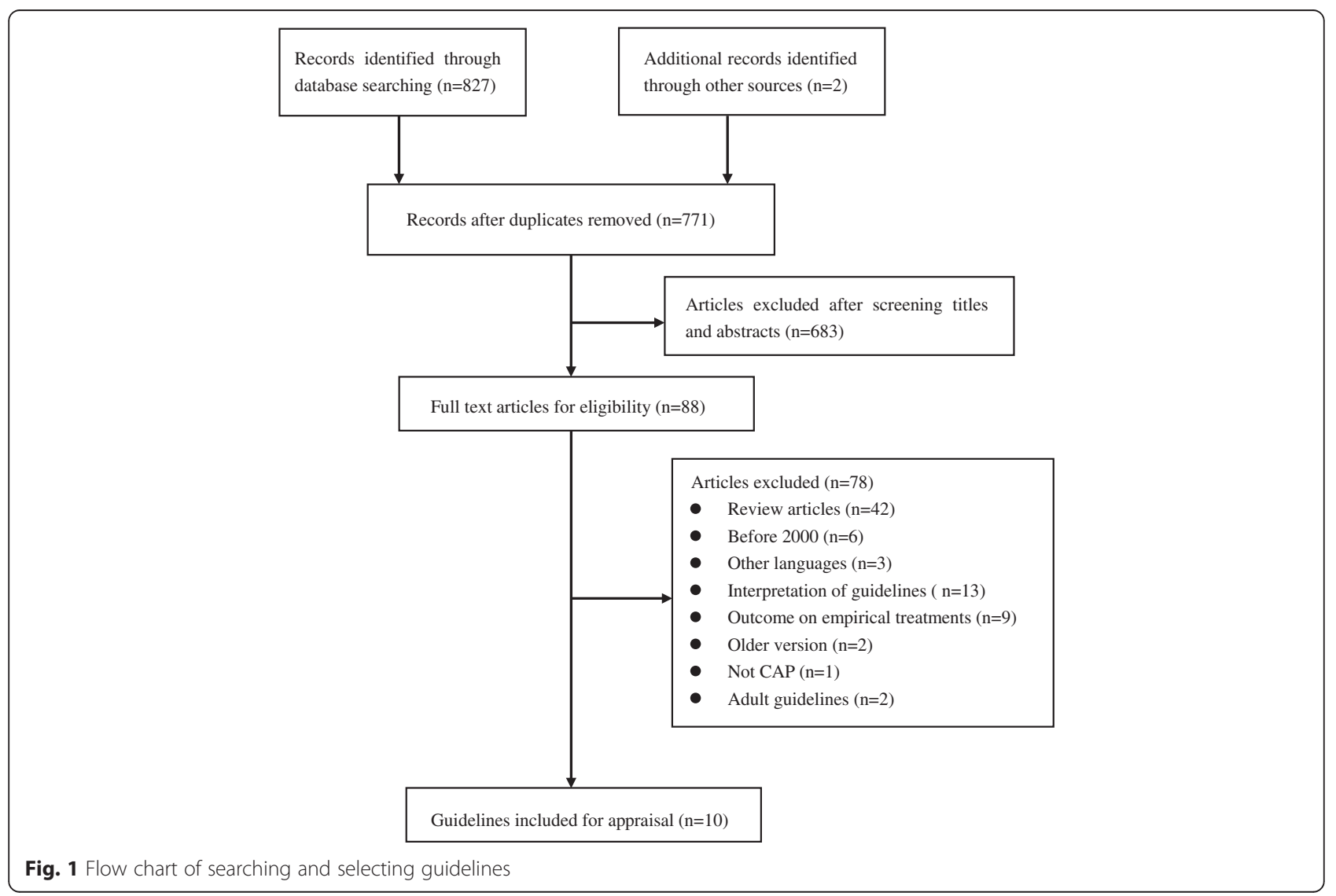


Table 1 Characteristics of 10 included guidelines

\begin{tabular}{|c|c|c|c|c|c|c|}
\hline $\begin{array}{l}\text { Clinical practice } \\
\text { guideline }\end{array}$ & $\begin{array}{l}\text { Country or } \\
\text { region }\end{array}$ & $\begin{array}{l}\text { Language of } \\
\text { guidelines }\end{array}$ & $\begin{array}{l}\text { Publication } \\
\text { date }\end{array}$ & Affiliation or organization & $\begin{array}{l}\text { Developed } \\
\text { method }\end{array}$ & $\begin{array}{l}\text { Quality of } \\
\text { evidence }\end{array}$ \\
\hline [7] & United States & English & 2011 & $\begin{array}{l}\text { Pediatric Infectious Diseases Society and the } \\
\text { Infectious Diseases Society of America }\end{array}$ & Evidenced-based & GRADE \\
\hline [8] & United Kingdom & English & 2011 & $\begin{array}{l}\text { British Thoracic Society Community Acquired } \\
\text { Pneumonia in Children Guideline Group }\end{array}$ & Evidenced-based & $\begin{array}{l}\text { Self designed } \\
\text { grading system }\end{array}$ \\
\hline [10] & South African & English & 2005 & $\begin{array}{l}\text { Working Groups of the Paediatric Assembly } \\
\text { of the South African Thoracic Society }\end{array}$ & Literature review & $\begin{array}{l}\text { Not } \\
\text { mentioned }\end{array}$ \\
\hline$[13,14]$ & China & Chinese & 2013 & $\begin{array}{l}\text { Subspecialty Group of Respiratory Diseases, } \\
\text { The Society of Pediatrics, Chinese Medical } \\
\text { Association }\end{array}$ & Literature review & $\begin{array}{l}\text { Self designed } \\
\text { grading system }\end{array}$ \\
\hline [16] & Malaysia & English & 2004 & $\begin{array}{l}\text { Ministry of Health Malaysia Academy of } \\
\text { Medicine Maylaysia }\end{array}$ & Evidenced-based & SIGN \\
\hline [12] & Taiwan & English & 2007 & $\begin{array}{l}\text { Taiwan Pediatric Working Group for "Guideline } \\
\text { on the management of CAP in children" }\end{array}$ & Literature review & $\begin{array}{l}\text { Not } \\
\text { mentioned }\end{array}$ \\
\hline [9] & Japan & English & 2007 & $\begin{array}{l}\text { Japanese Society of Pediatric Pulmonology } \\
\text { and the Japanese Society for Pediatric } \\
\text { Infectious Diseases }\end{array}$ & Literature review & $\begin{array}{l}\text { Not } \\
\text { mentioned }\end{array}$ \\
\hline [15] & WHO & English & 2013 & Word Health Organization & Literature review & $\begin{array}{l}\text { Not } \\
\text { mentioned }\end{array}$ \\
\hline [11] & Canada & English & 2011 & $\begin{array}{l}\text { Canadian Paediatric Society, Infectious Diseases } \\
\text { and Immunization Committee }\end{array}$ & Literature review & $\begin{array}{l}\text { Not } \\
\text { mentioned }\end{array}$ \\
\hline [17] & United States & English & 2006 & Cincinnati children's hospital medical center & Evidenced-based & $\begin{array}{l}\text { Self designed } \\
\text { grading system }\end{array}$ \\
\hline
\end{tabular}

\section{Overall quality assessment of guideline}

3 CPGs $[7,8,17]$ were strongly recommended as results of the overall scores greater than $60 \% .4$ CPGs [10, 13, $15,16]$ were "recommended with modifications", whose scores between $30 \%$ and $60 \% .3$ CPGs $[9,11,12]$ were "not recommended" due to all items scores being less than $30 \%$. Finally, IDSA guideline [7] achieved a relative high score among the 10 guidelines. This provides a reference of methodology for developing other CAP guidelines. The details of the appraisal results are presented in Table 2. AGREE II domain scores are plotted for each guideline for comparison are showed in Fig. 2.

Table 2 Standardized scores of each domain by AGREE II of guidelines

\begin{tabular}{|c|c|c|c|c|c|c|c|c|}
\hline Guideline & $\begin{array}{l}\text { Scope and } \\
\text { purpose (\%) }\end{array}$ & $\begin{array}{l}\text { Stakeholder } \\
\text { involvement (\%) }\end{array}$ & $\begin{array}{l}\text { Rigor of } \\
\text { development (\%) }\end{array}$ & $\begin{array}{l}\text { Clarity of } \\
\text { presentation (\%) }\end{array}$ & $\begin{array}{l}\text { Applicability } \\
(\%)\end{array}$ & $\begin{array}{l}\text { Editorial } \\
\text { independence (\%) }\end{array}$ & ICC & Overall assessment \\
\hline [7] & 95.83 & 73.61 & 79.17 & 94.44 & 54.17 & 87.50 & 0.82 & $\begin{array}{l}\text { Strongly } \\
\text { recommended }\end{array}$ \\
\hline [8] & 93.06 & 37.50 & 79.69 & 93.06 & 61.46 & 58.33 & 0.73 & $\begin{array}{l}\text { Strongly } \\
\text { recommended }\end{array}$ \\
\hline [10] & 81.95 & 34.72 & 32.29 & 76.39 & 35.41 & 33.33 & 0.88 & $\begin{array}{l}\text { Recommended with } \\
\text { modifications }\end{array}$ \\
\hline$[13,14]$ & 80.56 & 45.83 & 30.21 & 80.56 & 33.33 & 0 & 0.88 & $\begin{array}{l}\text { Recommended with } \\
\text { modifications }\end{array}$ \\
\hline [16] & 79.17 & 76.39 & 60.94 & 86.11 & 33.33 & 0 & 0.84 & $\begin{array}{l}\text { Recommended with } \\
\text { modifications }\end{array}$ \\
\hline [12] & 23.61 & 11.11 & 19.27 & 86.11 & 17.71 & 0 & 0.91 & Not recommended \\
\hline [9] & 61.11 & 9.70 & 23.44 & 83.33 & 25.00 & 0 & 0.91 & Not recommended \\
\hline [15] & 52.78 & 48.61 & 32.81 & 73.61 & 35.42 & 29.1 & 0.69 & $\begin{array}{l}\text { Recommended with } \\
\text { modifications }\end{array}$ \\
\hline [11] & 30.56 & 15.28 & 17.19 & 69.44 & 31.25 & 0 & 0.86 & Not recommended \\
\hline [17] & 91.67 & 75.00 & 74.48 & 90.28 & 47.92 & 29.17 & 0.82 & $\begin{array}{l}\text { Strongly } \\
\text { recommended }\end{array}$ \\
\hline $\begin{array}{l}\text { Mean } \\
\text { (range) }\end{array}$ & $\begin{array}{l}69.03 \\
(23.61-95.83)\end{array}$ & $\begin{array}{l}42.78 \\
(9.70-76.39)\end{array}$ & $\begin{array}{l}44.95 \\
(17.19-79.69)\end{array}$ & $\begin{array}{l}83.33 \\
(69.44-94.44)\end{array}$ & $\begin{array}{l}37.50 \\
(17.71-61.46)\end{array}$ & $\begin{array}{l}23.74 \\
(0-87.50)\end{array}$ & / & / \\
\hline
\end{tabular}




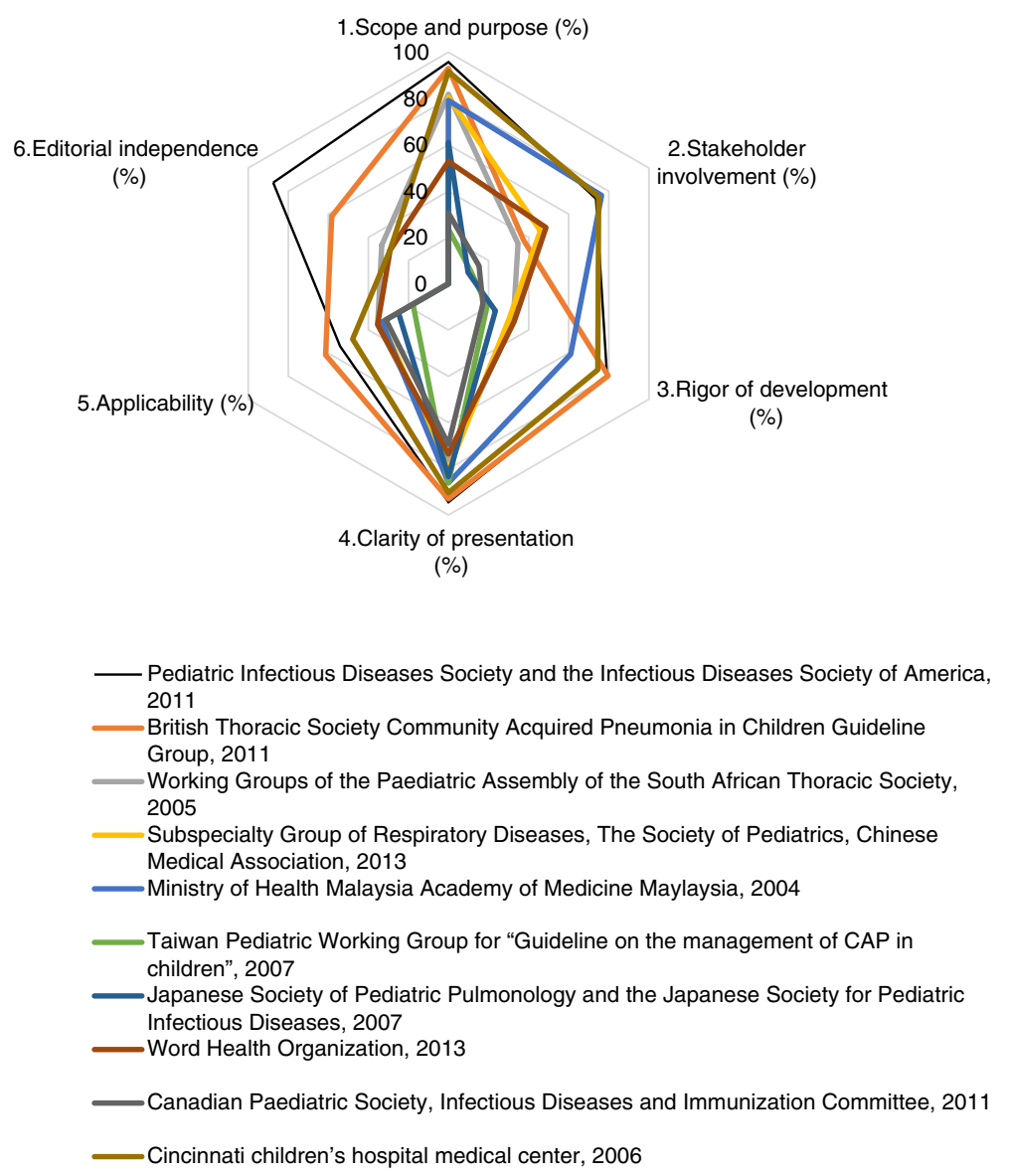

Fig. 2 AGREE II domain scores are plotted for each guideline for comparison

Of the guidelines involved, 4 were evidence-based guidelines which processed details of evidence scale, on the other hand, the remaining 6 were more consensuses than evidence-based guidelines. Compared with non evidence-based guidelines, evidence-based guidelines obtained significant higher scores in nearly all domains except "editorial independence". Table 3 shows a subgroup analysis of the involved guidelines.

\section{Discussion}

This study discussed a qualitative evaluation of the CPGs on CAP in children with the AGREE II guideline assessment. Eventually, 10 guidelines were included. In this study, we demonstrated that the scores of CAP guidelines were higher than an average international quality level [18], especially "Scope and purpose" and "Clarity of presentation". Compared to the guidelines published from 1980 to 2007, current guidelines could specifically describe the purpose of the guidelines and also clearly present the recommendation. However, in some domains the scores were much lower when compared with contemporary guidelines in respect to pediatric infectious diseases [19], such as "rigour of development" and "editorial independence". The average

Table 3 Comparison of mean quality scores among evidence-based guidelines and non evidence-based guidelines

\begin{tabular}{|c|c|c|c|c|c|c|}
\hline \multirow[t]{2}{*}{ Subgroup } & \multicolumn{6}{|l|}{ Domain (Mean \pm SD) } \\
\hline & Scope and purpose (\%) & $\begin{array}{l}\text { Stakeholder } \\
\text { involvement (\%) }\end{array}$ & $\begin{array}{l}\text { Rigor of } \\
\text { development (\%) }\end{array}$ & $\begin{array}{l}\text { Clarity of } \\
\text { presentation (\%) }\end{array}$ & Applicability (\%) & $\begin{array}{l}\text { Editorial } \\
\text { independence \% }\end{array}$ \\
\hline Evidence-based guideline & $89.93 \pm 7.38$ & $65.63 \pm 18.78$ & $73.57 \pm 8.74$ & $90.97 \pm 3.67$ & $49.22 \pm 11.95$ & $43.75 \pm 37.65$ \\
\hline Non Evidence-based guideline & $55.10 \pm 24.51^{*}$ & $27.54 \pm 17.71^{*}$ & $25.87 \pm 6.83^{*}$ & $78.24 \pm 6.25^{*}$ & $29.69 \pm 7.02^{*}$ & $10.41 \pm 16.17$ \\
\hline
\end{tabular}

Data are presented as mean \pm standard deviation. ${ }^{*} P<0.05$ 
score of the evidence-based guidelines on pediatric infectious diseases respectively was $76.04 \%$ and $81.25 \%$. Hence, there is still potential improvement with respect to qualities of pediatric CAP guidelines.

It was concluded from our results that CPGs tackling CAP on children account for a small amount compared with adults. A great number of countries or associations ignored to develop guidelines which are targeted to this particular group. Pediatric patients are tend to be more vulnerable in nature, therefore, it is essential to ensure that guidelines are developed under strict criteria. On the other hand, a great number of organizations failed to translate the CAP guidelines into English and hindered the efficiency of health science communication. Efforts are needed to translate guideline into a universal language and to assist health professions in better mastering strictly developed guidelines and to rectify discrepancies and promote evidence-based practices to enhance patient outcomes.

In our study, it should be noted that "scope and purpose" and "clarity of presentation" achieved a relative high scores among the six domains, which indicated that most guidelines fully satisfied this criteria. Most guidelines could fully describe the overall objective and their specific clinical issues. For "stakeholder involvement", relevant professionals in the development process were involved in most guidelines and target population was declared. However, the guideline developers did not seek the preference of target populations resulting in a decrease in score of this domain.

"Rigour of development" was considered to be one of the most crucial domain for the assessment of guideline development. In our study, this domain varied in guidelines, for evidence based guideline, it obtained higher scores, while consensus not. A strong recommendation should not solely be based on expert opinion. Guideline developers should adhere to a standardized evidencebased evaluation system. In this study, only $4[7,8,16$, 17] guidelines clearly described the criteria for selecting the evidence, as well as strengths and limitations of the evidence. The quality may be improved by involving methodologists in the guideline development. It is also expected that CPGs should grade the quality of evidence on an existing well recognized grading system such as GRADE (Grading of Recommendations Assessment, Development and Evaluation). GRADE grading system was first introduced in 2004 for access the quality of evidence and strength of recommendation. Gradually, it was recognized by more than 30 organizations including WHO and Cochrane Collaboration. Although the 10 guidelines included in our study were published after 2005, only 1 CPG [7] use the GRADE system. 1 CPG [16] use SIGN (The Scottish Intercollegiate Guidelines Network) and 3 CPGs $[8,13,17]$ guidelines used their own developing system. We suggest further guidelines should use a comparable uniform grading system to evaluate the quality of evidence and strength of recommendations. In this domain, a procedure of updating the guidelines was neglected in most guidelines. Only 2 CPGs $[16,17]$ referred the updating procedures. It is recommended that guidelines be updated at 3-year intervals, as new evidence may result in substantial changes to the recommendations [20].

Our study found that "applicability" scored low among the six domains. A great number of guidelines lack of describing facilitators and barriers to its application, advice and/or tools on how the recommendations can be put into practice. Guideline would rate high if the potential resource implications of applying the recommendations had been considered, such as a summary document, a quick reference guide, and educational tool. In order to ensure the feasibility of clinical practice, it is also suggested that a pilot test for the applicability of new guidelines should be performed before its publication. These items should be taken into consideration when the following guidelines are developing.

Editorial independence was also neglected in a great deal of guidelines. Only 3 [7, 10, 17] guidelines reported detailed information on potential conflicts of interest. Conflicts of interest are the most common source of bias in guideline development [21]. There should be an explicit statement that all group members have declared whether they have any competing interests. It may be suggested by making it mandatory for guideline developers to list the potential competing interests in the documents.

A strength of our study is that we used AGREE II instrument to assess the methodological quality of guidelines related to CAP in children, which has no related appraisal research on this particular group. Furthermore, our team consisted of pediatric clinical experts and pharmacist with extensive experience in clinical guidelines appraisal.

There are limitations within this study that should be noted. Firstly, the guidelines involved are confined to English and Chinese. Secondly, the literature search only identified published guidelines in pediatric pneumonia. It is possible that some guidelines may have been missed by the search, especially those that combined pediatric and adult recommendations. Thirdly, the AGREE II instrument is a tool that assesses the methodological rigour and transparency in which a guideline is developed [22, 23]. It informs what information and how information ought to be reported in guideline. However, there is no threshold for discrimination from high quality to low quality CPGs. Thus, the guidelines quality would be left to the appraisers to identify and the scores of an AGREE II evaluation have 
to be interpreted with caution and confined to a particular situation.

\section{Conclusion}

Overall, this study appraised quality scores of the CPGs on CAP in children. The appraisal results showed acceptable. The developers are suggested to pay more attention to rigour of development, applicability, and editorial independence during the development process. The AGREE II instrument should be adopted by guideline developers to improve the applicability of guidelines.

\begin{abstract}
Abbreviations
AGREE II, the appraisal of guidelines for research and evaluation II; CAP, community-acquired pneumonia; CBM, Chinese databases were Chinese Biomedical Literature Database; CNKI, China National Knowledge Internet; CPGs, clinical practice guidelines; EBM, evidence-based medicine; GIN, Guidelines International Network; GRADE, Grading of Recommendations Assessment, Development and Evaluation; ICC, intraclass correlation coefficient; IDSA, Infectious Diseases Society of America; NGC, National Guideline Clearinghouse; SIGN, The Scottish Intercollegiate Guidelines Network
\end{abstract}

\section{Acknowledgements}

The authors gratefully acknowledge the support by WHO-China Biennial Collaborative Projects 2014-2015.

\section{Funding}

The Project was supported by WHO-China Biennial Collaborative Projects 2014-2015.

\section{Availability of data and materials}

All the data supporting the findings is contained within the manuscript.

\section{Authors' contributions}

LBZ and XLW conceived and designed the study. ZWX and LBZ searched the database and consulting ADS when there was a disagreement. ZWX, LS, JL and YG appraised the guidelines. XLW, ADS and BPX participated in the phase of discussion on results and critically reviewed the work. ZWX wrote the initial draft and was responsible for data management. LBZ, ADS and XLW provided critical revision on subsequent drafts and approved of the manuscript in its final form. All authors read and approved the final manuscript.

\section{Competing interests}

The authors declare that they have no competing interests.

\section{Consent for publication}

Not applicable.

\section{Ethics approval and consent to participate}

Not applicable.

\section{Author details}

'Department of Pharmacy, Beijing Children's Hospital, Capital Medical University, Beijing 100045, China. ${ }^{2}$ School of Pharmaceutical Science, Peking University, Beijing 100191, China. ${ }^{3}$ Key Laboratory of Pediatric Respiratory Infection Diseases, Beijing Pediatric Research Institute, Beijing Children's Hospital, Capital Medical University, Beijing 100045, China. ${ }^{4}$ Department of Respiratory, Beijing Children's Hospital, Capital Medical University, Beijing 100045, China.

Received: 8 August 2015 Accepted: 19 July 2016

Published online: 02 August 2016

\section{References}

1. Ranganathan SC, Sonnappa S. Pneumonia and other respiratory infections. Pediatr Clin North Am. 2009;56(1):135-56. xi.

2. Chisti MJ, Tebruegge M, La Vincente S, Graham SM, Duke T. Pneumonia in severely malnourished children in developing countries - mortality risk, aetiology and validity of WHO clinical signs: a systematic review. Tropical Med Int Health. 2009;14(10):1173-89.

3. Atkinson M, Yanney M, Stephenson T, Smyth A. Effective treatment strategies for paediatric community-acquired pneumonia. Expert Opin Pharmacother. 2007;8(8):1091-101.

4. Rudan I, Boschi-Pinto C, Biloglav Z, Mulholland K, Campbell H. Epidemiology and etiology of childhood pneumonia. Bull World Health Organ. 2008;86(5):408-16.

5. Brouwers MC, Kho ME, Browman GP, Burgers JS, Cluzeau F, Feder G, Fervers B, Graham ID, Grimshaw J, Hanna SE, et al. AGREE II: advancing guideline development, reporting, and evaluation in health care. Prev Med. 2010;51(5):421-4.

6. Vlayen J, Aertgeerts B, Hannes K, Sermeus W, Ramaekers D. A systematic review of appraisal tools for clinical practice guidelines: multiple similarities and one common deficit. Int J Qual Health Care. 2005; 17(3):235-42.

7. Bradley JS, Byington CL, Shah SS, Alverson B, Carter ER, Harrison C, Kaplan SL, Mace SE, McCracken Jr GH, Moore MR, et al. The management of community-acquired pneumonia in infants and children older than 3 months of age: clinical practice guidelines by the Pediatric Infectious Diseases Society and the Infectious Diseases Society of America. Clin Infect Dis. 2011;53(7):e25-76.

8. Harris M, Clark J, Coote N, Fletcher P, Harnden A, McKean M, Thomson A, British Thoracic Society Standards of Care C. British Thoracic Society guidelines for the management of community acquired pneumonia in children: update 2011. Thorax. 2011;66 Suppl 2:ii1-23.

9. Uehara S, Sunakawa K, Equchi H, Ouchi K, Okada K, Kurosaki T, Suzuki H, Tsutsumi H, Haruta T, Mitsuda T, et al. Japanese Guidelines for the Management of Respiratory Infectious Diseases in Children 2007 with focus on pneumonia. Pediatr Int. 2011:53(2):264-76.

10. Zar HJ, Jeena P, Argent A, Gie R, Madhi SA, Working Groups of the Paediatric Assembly of the South African Thoracic S. Diagnosis and management of community-acquired pneumonia in childhood-South African Thoracic Society Guidelines. S Afr Med J. 2005:95(12 Pt 2):977-81. 984-990.

11. Le Saux N, Robinson J. Pneumonia in healthy Canadian children and youth: Practice points for management. Paediatr Child Health. 2011;16(7):417-24.

12. Lee $\mathrm{Pl}$, Chiu CH, Chen PY, Lee CY, Lin TY, Taiwan Pediatric Working Group for Guideline on the Management of CAPiC. Guidelines for the management of community-acquired pneumonia in children. Acta Paediatr Taiwan. 2007:48(4):167-80

13. Subspecialty Group of Respiratory Diseases TSoPCMA, Editorial Board CJoP. Guidelines for management of community acquired pneumonia in children (the revised edition of 2013) (I). Zhonghua Er Ke Za Zhi. 2013;51(10):745-52.

14. Subspecialty Group of Respiratory Diseases TSoP, Chinese Medical Association The Editorial Board CJoP. Guidelines for management of community acquired pneumonia in children (the revised edition of 2013) (II). Zhonghua Er Ke Za Zhi. 2013;51(11):856-62.

15. World Health Organization. Pocket book of hospital care for children Guidelines for the management of common illnesses with limited resources. Geneva: WHO Press; 2005. p. 72-81.

16. Azizi H NM, Bilkis B: Clinical Practice Guidelines on pneumonia and respiratory tract infections in children. Academy of Medicine of Malaysia Clinical Practice Guidelines (CPGs). 2002, Available at: http://pdfsr.com/pdf/ 2004-cpg-rational-antibiotic-utilisation-in-selected-paediatric-conditions. (accessed Jan10,2013).

17. Community Acquired Pneumonia Guideline Team Cincinnati Children's Hospital Medical Center: Evidence-based care guideline for medical management of Community Acquired Pneumonia in children 60 days to 17 years of age. http://www.docin.com/p-375158193.html (Guideline 14):1-16.

18. Alonso-Coello P, Irfan A, Sola I, Gich I, Delgado-Noguera M, Rigau D, Tort S, Bonfill X, Burgers J, Schunemann $\mathrm{H}$. The quality of clinical practice guidelines over the last two decades: a systematic review of guideline appraisal studies. Qual Saf Health Care. 2010;19(6):e58.

19. Wilby KJ, Black EK, MacLeod C, Wiens M, Lau TT, Paiva MA, Gorman S. Critical appraisal of clinical practice guidelines in pediatric infectious diseases. Int J Clin Pharm. 2015;37(5):1-9.

20. Shekelle PG, Ortiz E, Rhodes S, Morton SC, Eccles MP, Grimshaw JM, Woolf SH. Validity of the Agency for Healthcare Research and Quality clinical practice guidelines: how quickly do guidelines become outdated? JAMA. 2001:286(12):1461-7. 
21. Detsky AS. Sources of bias for authors of clinical practice guidelines. CMAJ 2006;175(9):1033-5.

22. Brouwers MC, Kho ME, Browman GP, Burgers JS, Cluzeau F, Feder G, Fervers B, Graham ID, Grimshaw J, Hanna SE, et al. AGREE II: advancing guideline development, reporting and evaluation in health care. CMAJ. 2010;182(18):E839-842.

23. MacDermid JC, Brooks D, Solway S, Switzer-McIntyre S, Brosseau L, Graham ID. Reliability and validity of the AGREE instrument used by physical therapists in assessment of clinical practice guidelines. BMC Health Serv Res. 2005;5(1):18

Submit your next manuscript to BioMed Central and we will help you at every step:

- We accept pre-submission inquiries

- Our selector tool helps you to find the most relevant journal

- We provide round the clock customer support

- Convenient online submission

- Thorough peer review

- Inclusion in PubMed and all major indexing services

- Maximum visibility for your research

Submit your manuscript at www.biomedcentral.com/submit 